Berkala Ilmu Perpustakaan dan Informasi, Vol. 13, No. 1, Juni 2017, Hal. 56-63 DOI: http://10.22146/bip.26042

ISSN 1693-7740 (Print), ISSN 2477-0361 (Online)

Tersedia online di https://jurnal.ugm.ac.id/bip

\title{
PENCAPAIAN MASYARAKAT INFORMASI DITINJAU MELALUI IMPLEMENTASI PROGRAM KELOMPOK INFORMASI MASYARAKAT (KIM): STUDI KASUS IMPLEMENTASI PROGRAM KIM DI JAWA TIMUR DI WILAYAH RURAL (KIM NGLANDUK DAN KIM WARUREJO) DAN WILAYAH URBAN (KIM MOJO DAN KIM SWARAGUNA)
}

\author{
Reni Puspita Sari ${ }^{1}$ \\ ${ }^{1}$ Mahasiswa S2 Sosiologi FISIPOL UGM \\ Email : renipuspita92@yahoo.co.id
}

Naskah diterima: 10 April 2017, direvisi: 22 Mei 2017, disetujui: 12 Juni 2016

\begin{abstract}
ABSTRAK
Penelitian ini menilai tingkat pencapaian masyarakat informasi ditinjau melalui implementasi program KIM. KIM ialah Kelompok Informasi Masyarakat sebuah program pemerintah Indonesia untuk mengupayakan terwujudnya masyarakat informasi di Indonesia. KIM di desain sebagai kelompok yang terbentuk secara mandiri sehingga dalam perkembangannya akan menjadi kelompok masyarakat yang independen. Tujuan dari penelitian ini ialah untuk melihat bagaimana pencapaian masyarakat informasi ditinjau melalui implementasi program KIM. Sehingga mampu memberikan masukan kepada pemerintah terkait bagaimana pencapaian masyarakat informasi dan masukan pula terkait program KIM. Dengan pendekatan penelitian kualitatif, metode yang digunakan dalam penelitian ini ialah studi kasus. Studi kasus dilakukan di dua wilayah yang berbeda yakni wilayah rural dan juga wilayah urban di Jawa Timur. Berdasarkan hasil temuan yang diperoleh, bahwa kondisi masyarakat masih jauh dari harapan terwujudnya masyarakat informasi. Kondisi masyarakat masih berada pada tingkatan masyarakat sadar informasi, bahkan di wilayah rural masih banyak masyarakat yang kurang sadar akan informasi. Hal ini disebabkan oleh implementasi program KIM masih kurang maksimal dan masih mendapatkan banyak kendala.
\end{abstract}

Kata Kunci : Masyarakat informasi, Kelompok Informasi Masyarakat, KIM

\section{ABSTRACT}

This study examines the level of achievement of the information society through the implementation of the Kelompok Informasi Masyarakat (KIM) program. KIM is a program initiated by Indonesian government to seek the realization of the information society in Indonesia. KIM is designed as a group formed independently so that the development will depend on the community group. The purpose of this study was to understand how the achievement of the information society through the implementation of KIM. It also aims to provide recomendations to the government related tothe achievement of the information society and KIM program. With a qualitative research approach, the method used in this research was a case study. The case studies were conducted in two different area: rural and urban areas in East Java. Based on the results, the condition of the people is still far from the expectation of the information society. In rural areas there were still many people who were less aware of the information. It showed that the KIM program implementation was still under expectation with several obstacles.

Keywords: Information society, Kelompok Informasi Masyarakat, KIM 


\section{A. PENDAHULUAN}

Saat ini Indonesia tengah dalam upaya mewujudkan masyarakat informasi. Pada tahun 2006 Indonesia mengikuti sebuah konferensi World Summit on the Information Society (WSIS) di Geneva. Melalui Menteri Kominfo saat itu Sofyan A. Djali, Indonesia telah sepakat untuk mewujudkan masyarakat informasi di Indonesia. Forum WSIS merupakan forum yang menghasilkan diakuinya teknologi secara formal sebagai salah satu sarana utama dalam rangka memecahkan masalah (summit of solutions), untuk menjembatani atau merubah masalah-masalah kesenjangan digital (digital devide) menjadi peluang digital (digital opportunity), untuk mempromosikan perdamaian, pembangunan yang berkelanjutan, demokrasi, transparansi dan pengelolaan negara yang baik (goodgovernance).

Salah satu program yang dibuat oleh pemerintah untuk mendukung terwujudnya masyarakat informasi di Indonesia adalah dibentuknya program KIM atau Kelompok Informasi Masyarakat. Program ini merupakan sebuah program yang ditujukan untuk masyarakat agar mampu mengoptimalisasi manfaat informasi di kehidupan mereka. Pemerintah mengupayakan setiap daerah di Indonesia untuk membentuk kelompok-kelompok masyarakat yang berkonsentrasi pada penyerapan informasi, pemanfaatan dan penyebaran informasi. Selain itu, program tersebut juga dapat dijadikan sebagai sarana untuk memperkenalkan teknologi informasi dan komunikasi kepada masyarakat. Pada dasarnya kelompok ini berusaha untuk memaksimalkan informasi melalui berbagai lini untuk mampu bertahan di tengah persaingan bisnis yang ketat, sehingga nantinya masyarakat Indonesia mampu bersaing dengan masyarakat dari negara lain.

Pemerintah mendesain program KIM agar dibentuk secara mandiri oleh masyarakat. Karena program KIM diharapkan akan membentuk kelompok-kelompok masyarakat yang independen dan mandiri. Visi dari kelompok ini ialah memberdayakan masyarakat menjadi lebih produktif, lebih berpartisipasi aktif atas segala sesuatu yang terjadi di sekitarnya sehingga akan terwujud masyarakat informasi. Dengan berbasis informasi, masyarakat diharapkan mampu untuk memberikan kontrol dan menjadi bagian dari keputusan ekonomi, sosial dan juga budaya. Masyarakat informasi merupakan tujuan dan citacita bersama seluruh dunia. Meningkatkan kualitas hidup dengan memanfaatkan teknologi informasi dan komunikasi adalah harapan dari terciptanya masyarakat informasi.

Oleh karenanya, penelitian ini bermaksud memberikan gambaran mengenai bagaimana pencapaian masyarakat informasi ditinjau melalui implementasi program KIM di masyarakat. Selain itu, bagaimana upaya pemerintah untuk mewujudkan masyarakat informasi melalui implementasi program. Sejauh mana tercapainya masyarakat informasi di Indonesia. KIM menjadi sebuah obyek penelitian yang menarik karena-serupa dengan program Kelompencapir. Sehingga menarik untuk melihat bagaimana implementasi program KIM pada kondisi masyarakat yang berbeda dengan masa-masa berjayanya program Kelompencapir.

Penelitian ini membandingkan KIM yang berada di wilayah rural dan KIM yang berada di wilayah urban di Jawa Timur. Pembandingan ini dimaksudkan untuk melihat bagaimana kecenderungan dari implementasi program KIM di wilayah dan kondisi masyarakat yang berbeda. Sehingga akan memberikan gambaran yang lebih detail mengenai bagaimana pencapaian terwujudnya masyarakat informasi di Indonesia pada wilayah dan kondisi masyarakat yang berbeda. Penelitian ini melihat bagaimana proses pembentukan kelompok dan aktivitas-aktivitas yang dijalankan dalam keseharian untuk mencapai tujuan terwujudnya masyarakat informasi. Diuraikan apa saja hambatan yang dihadapi selama proses implementasi program KIM, dan capaian fungsi KIM apa saja yang telah diraih oleh masing-masing KIM.

\section{Tujuan Penelitian}

Penelitian ini bertujuan untuk mengetahui bagaimana perwujudan masyarakat informasi di Indonesia melalui implementasi program KIM.

\section{Manfaat Penelitian}

Penelitian ini bermanfaat untuk memberikan informasi mengenai bagaimana pencapaian terwujudnya masyarakat informasi melalui implementasi program KIM dengan kondisi wilayah dan karakteristik masyarakat yang berbeda yakni di wilayah rural (KIM Warurejo dan KIM Nglanduk) dan juga di wilayah urban (KIM Swaraguna dan KIM Mojo) di Jawa Timur. Selain itu, melalui penelitian ini juga memberikan informasi-informasi yang mampu dijadikan rujukan dalam memperbaiki program KIM dan juga evaluasi untuk pihak terkait lainnya agar nantinya tercipta sebuah kesinambungan semua pihak untuk mewujudkan masyarakat informasi Indonesia. 


\section{B. TINJAUAN PUSTAKA}

Untuk mengeksplorasi penelitian ini dibutuhkan beberapa teori yaitu teori tentang masyarakat informasi, kelompok informasi masyarakat, literasi informasi, posisi Indonesia di era informasi dan program KIM.

\section{Masyarakat Informasi}

Masyarakat informasi merupakan masyarakat yang memiliki karakteristik penggunaan informasi yang tinggi di setiap harinya di berbagai aspek baik sosial, pendidikan maupun bisnis (Polyviou, 2007:3). Sebagai sebuah definisi, masyarakat informasi sesungguhnya adalah konsep yang mulai muncul dan digunakan sejak tahun 1970-an. Konsep tersebut dikembangkan oleh Daniel Bell pada awal tahun 1970-an melalui prediksinya ketika itu tentang masyarakat pasca industri atau post industrial society.

Dalam masyarakat terdapat tiga tingkatan dari aspek informasi (Akhmad Djunaedi, 2015:20). Tingkat pertama adalah masyarakat sadar informasi, yaitu masyarakat yang sudah sadar bahwa informasi diperlukan untuk meningkatkan daya saing. Tingkat kedua adalah masyarakat kaya informasi, yaitu masyarakat yang sudah cukup banyak mempunyai informasi sehingga cukup mempunyai daya saing (kompetitif). Tingkat ketiga adalah masyarakat berbasis pengetahuan (knowledge based society), yaitu masyarakat kaya informasi yang dalam mengambil keputusan sehari-hari mendasarkan diri pada pengetahuan. Dalam hal ini pengetahuan tersedia secara memadai dan mudah diakses oleh masyarakat. Informasi yang berlimpah mendorong diolahnya informasi tersebut menjadi pengetahuan.

\section{Kelompok Informasi Masyarakat}

Community information adalah kelompok informasi yang berfokus pada masyarakat untuk memiliki kemampuan dan pemanfaatan terhadap informasi demi kelangsungan hidup dan pertumbuhan masyarakat. Informasi yang dibagikan kepada masyarakat dari community information adalah informasi yang diperlukan oleh anggota masyarakat untuk membuat penggunaan efektif dari sumber daya yang tersedia di sekitar mereka.

Program KIM ini diarahkan pemerintah untuk mampu membantu mewujudkan masyarakat yang mampu mendayagunakan teknologi informasi dan juga komunikasi. Program ini juga merupakan sebuah perwujudan program pemerintah terkait penyelenggaraan diseminasi informasi yang tidak lagi dimonopoli oleh pemerintah. Sehingga Program KIM ini dirancang untuk membantu pemerintah melakukan diseminasi informasi kepada masyarakat luas. Hal ini dikarenakan lembaga-lembaga seperti KIM memiliki hubungan yang lebih dekat dengan masyarakat sehingga dianggap lebih mengetahui tentang kebutuhan dan keadaan masyarakat.

\section{Literasi Informasi}

Istilah literasi informasi selalu dikaitkan dengan computer literacy, library skills dan critical thinking yang merupakan sebagai pendukung terhadap perkembangan literasi informasi. Menurut Verzosa (2009), literasi informasi dapat diartikan sebagai kemampuan untuk mengakses dan mengevaluasi informasi secara efektif untuk memecahkan masalah dan membuat keputusan. Seseorang yang memiliki literasi informasi adalah orang yang tahu bagaimana belajar untuk belajar (learning how to learn) karena mereka biasa tahu bagaimana informasi itu dikelola, cara menemukan, dan menggunakan informasi sesuai dengan etika yang berlaku.

\section{Posisi Indonesia di Era Informasi}

Teknologi merupakan elemen yang semakin penting dari globalisasi dan daya saing dan percepatan dalam tingkat teknologi mengubah dan pra-syarat yang diperlukan untuk berpartisipasi secara efektif dalam globalisasi membuat lebih sulit bagi banyak negara berkembang untuk bersaing (Dahlman, 2015:29). Di era informasi saat ini Indonesia berdasarkan Global Competitiveness Index tahun 2016-12017 daya saing Indonesia berada pada peringkat 41 dari 138 negara. Peringkat ini menurun karena pada tahun sebelumnya Indonesia menempati peringkat 37. Dari keseluruhan penilaian, Indonesia memiliki nilai terendah pada indeks penyerapan teknologi yaitu hanya sebesar 3,5 dari skala 7 .

\section{Program KIM}

Latar belakang program KIM ialah untuk meningkatkan kemampuan masyarakat sehingga berdaya dan dapat hidup layak serta mampu mengatasi permasalahan di masa yang akan datang. Dasar hukum KIM ialah Permenkominfo No:8/PER/MENKOMINFO/6/ 2010 tentang Pedoman Pengembangan dan Pemberdayaan Lembaga Komunikasi Sosial. KIM dibentuk dan dijalankan untuk memenuhi tujuan yang bersangkutan dengan kesejahteraan masyarakat. KIM berasaskan Pancasila yang menjunjung tinggi obyektivitas keabsahan dan keterbukaan informasi untuk kemaslahatan anggota masyarakat dan bangsa. 
Visi KIM ialah terwujudnya KIM yang inovatif dalam meningkatkan nilai tambah bagi masyarakat melalui pendayagunaan informasi dan komunikasi dalam rangka mencapai masyarakat informasi yang sejahtera. KIM memiliki banyak fungsi, yaitu KIM sebagai wahana informasi, KIM sebagai mitra dialog pemerintah, KIM sebagai lembaga yang memiliki nilai ekonomi, KIM sebagai sarana peningkatan literasi informasi, media massa dan teknologi komunikasi. Atas dasar fungsi ini, dalam penelitian ini digunakan sebagai indikator capaian KIM. Aktivitas pokok KIM ialah akses informasi, mendiskusikan informasi yang diperoleh, mengimplementasikan informasi yang diperoleh, mengembangkan jaringan, mendiseminasikan informasi ke lingkungan sekitar dan menyerap aspirasi masyarakat.

\section{METODE PENELITIAN \\ 1. Metode Penelitian}

Pendekatan penelitian yang digunakan adalah pendekatan kualitatif (qualitative research). Metodologi kualitatif digunakan oleh peneliti sebagai prosedur penelitian terhadap obyek penelitian yakni KIM di wilayah rural dan urban di Jawa Timur. Penelitian ini merupakan penelitian studi kasus. Studi kasus dipilih oleh peneliti karena dapat menyajikan pandangan dari obyek yang diteliti menyajikan uraian yang menyeluruh tentang obyek penelitian. Studi kasus merupakan sarana efektif untuk menunjukkan hubungan antara peneliti dan informan.

\section{Obyek Penelitian}

\begin{tabular}{|l|l|l|}
\hline & Wilayah Urban & Wilayah Rural \\
\hline $\begin{array}{l}\text { Kota/ } \\
\text { Kabupaten }\end{array}$ & Kota Surabaya & Kabupaten Madiun \\
\hline $\begin{array}{l}\text { Knfompok } \\
\text { Masyarakat } \\
\text { (KIM) }\end{array}$ & $\begin{array}{l}\text { KIM Mojo dan KIM } \\
\text { Swaraguna }\end{array}$ & $\begin{array}{l}\text { KIM Nglanduk dan } \\
\text { KIM Warurejo }\end{array}$ \\
\hline $\begin{array}{l}\text { Kondisi } \\
\text { Wilayah }\end{array}$ & $\begin{array}{l}\text { Padat penduduk, lahan } \\
\text { penuh dengan industri, } \\
\text { banyak terdapat gedung- } \\
\text { gedung perkantoran, } \\
\text { fasilitas umum } \\
\text { cenderung lengkap } \\
\text { seperti pasar, sekolah, } \\
\text { perguruan tinggi, rumah } \\
\text { sakit, pasar modern } \\
\text { (mall) }\end{array}$ & $\begin{array}{l}\text { Lahan pertanian } \\
\text { dibandingkan dengan } \\
\text { wilayah tempat tinggal } \\
\text { penduduk, fasilitas } \\
\text { yang tersedia kurang } \\
\text { memadai seperti pasar } \\
\text { tradisional, sekolah, } \\
\text { puskesmas }\end{array}$ \\
\hline $\begin{array}{l}\text { Kondisi } \\
\text { Masyarakat }\end{array}$ & $\begin{array}{l}\text { Masyarakat beragam } \\
\text { karena tingginya } \\
\text { urbanisasi, masyarakat } \\
\text { cenderung hidup secara } \\
\text { individual, masyarakat } \\
\text { memiliki pencaharian } \\
\text { yang lebih heterogen }\end{array}$ & $\begin{array}{l}\text { Masyarakat cenderung } \\
\text { homogen, hidup } \\
\text { dengan gotong royong } \\
\text { tinggi, mata } \\
\text { pencaharian } \\
\text { masyarakat mayoritas } \\
\text { bertani }\end{array}$ \\
\hline
\end{tabular}

\section{Teknik Pengumpulan Data}

Peneliti mengumpulkan data melalui wawancara atau indepth interview dan mengumpulkan data dari sumber-sumber data yang telah ada seperti data-data yang berkaitan dengan KIM.

\section{Teknik Analisis Data}

Teknik analisis data yang digunakan dalam penelitian ini mengacu pada konsep Milles \& Huberman (1992:20) yaitu interactive model yang mengklasifikasikan analisis data dalam tiga langkah, yaitu : 1. Reduksi data (data reduction) yaitu suatu proses pemilahan, pemusatan perhatian pada penyederhanaan, pengabstrakan dan transformasi data kasar yang muncul dari catatan-catatan tertulis di lapangan. 2. Penyajian data (display data). Data ini tersusun sedemikian rupa sehingga memberikan kemungkinan adanya penarikan kesimpulan dan pengambilan tindakan. Adapun bentuk yang lazim digunakan pada data kualitatif terdahulu adalah dalam bentuk teks naratif. 3. Penarikan kesimpulan (verifikasi).

\section{HASIL DAN PEMBAHASAN}

\section{Hasil Penelitian}

Implementasi program KIM Kominfo Jawa Timur dibedakan berdasarkan kategori wilayah yang berbeda. Implementasi program KIM dibedakan pada wilayah urban dan juga wilayah rural di Jawa Timur. Sehingga pada uraian mengenai hasil, peneliti juga membaginya berdasarkan kategori urban dan rural. Kelompok yang termasuk pada wilayah rural ialah KIM Warurejo dan KIM Nglanduk di Kabupaten Madiun. Sedangkan kelompok yang termasuk pada wilayah urban ialah KIM Mojo dan KIM Swaraguna di Kota Surabaya.

\section{a. Implementasi Program KIM di Wilayah Rural Jawa Timur}

1. Pembentukan KIM di Wilayah Rural (KIM Warurejo dan KIM Nglanduk)

Di Desa Nglanduk dan Desa Warurejo Kabupaten Madiun pembentukan KIM memiliki pola yang sama. Pembentukan KIM di dua wilayah rural ini bukan berdasarkan kerisauan masyarakat atas kebutuhan informasi, melainkan atas keinginan pemerintah agar tercipta kelompok informasi masyarakat di wilayah-wilayah tersebut. Pemerintah Kabupaten Madiun dengan sengaja membentuk KIM di seluruh wilayah Kabupaten Madiun. 
Setiap desa diwajibkan untuk memiliki kelompok informasi masyarakat. Oleh karenanya setiap Kepala Desa di wilayah Kabupaten Madiun menunjuk warganya untuk membentuk sebuah organisasi KIM.

2. Aktivitas KIM di Wilayah Rural (KIM Warurejo dan KIM Nglanduk)

KIM Warurejo maupun KIM Nglanduk, merupakan KIM yang cenderung pasif. Usai pembentukan dan turunnya surat keputusan, masing-masing KIM kurang berjalan seperti apa yang diharapkan dalam pembentukannya. Meskipun masing-masing KIM di Kabupaten Madiun memiliki blog, namun blog tersebut tidak dijalankan. Sehingga blog tersebut menjadi pasif tanpa ada pembaharuan.

2. Hambatan Implementasi Program KIM di Wilayah Rural (KIM Warurejo dan KIM Nglanduk)

Hambatan yang menjadi penghalang implementasi program KIM di wilayah rural ialah kurangnya rasa kepedulian dan kesadaran masyarakat terhadap KIM. Masyarakat di Desa Nglanduk dan juga di Desa Warurejo, kurangnya infrastruktur pendukung seperti jaringan internet, dan juga sedikitnya SDM yang mau ikut serta dalam menjalankan KIM di wilayah masing-masing.

3. Capaian KIM di Wilayah Rural (KIM Warurejo dan KIM Nglanduk)

Kedua KIM yang berada di wilayah rural ini mengalami beberapa hambatan yang menyebabkan tidak berjalannya program yang dimiliki, sehingga tidak ada aktivitas yang berjalan semenjak terbentuknya kelompok tersebut di desa masing-masing. Akibatnya KIM Nglanduk dan juga KIM Warurejo tidak memiliki sebuah pencapaian yang diraih hingga saat ini.

\section{b. Implementasi Program KIM di Wilayah Urban Jawa Timur}

1. Pembentukan KIM di Wilayah Urban (KIM Mojo dan KIM Swaraguna)

Pembentukan KIM di wilayah urban ini diawali dari penunjukkan salah seorang anggota masyarakat oleh Camat Gunung Anyar Seorang warga bernama Rizky Rahmadianti saat itu dianggap mampu dan memiliki kapasitas untuk membentuk KIM di wilayah kecamatan Gunung Anyar Surabaya. Pembentukan KIM Mojo dilakukan secara mandiri oleh masyarakat yaitu oleh seorang warga bernama Aminullah. Ia merasa bahwa keadaan masyarakat yang sangat minim informasi akan mempersulit kehidupan mereka. Sehingga ia merasa berkewajiban untuk berbagi informasi di masyarakat.

2. Aktivitas KIM di Wilayah Urban (KIM Mojo dan KIM Swaraguna)

KIM Swaraguna memiliki aktivitas rutin yaitu penyebaran informasi melalui media online. Kegiatan mencari informasi dan menuliskannya dalam media online seperti blog, maupun facebook adalah kegiatan yang paling utama. KIM Swaraguna lebih aktif dalam update informasi kepada masyarakat melalui facebook dan juga blog. Media yang biasa digunakan untuk penyebaran informasi secara online ialah facebook, whatsapp, twitter. Selain itu penyebaran informasi melalui media online dilakukan oleh KIM Mojo dengan melalui postingan-postingan yang di tulis langsung atau juga menyadur berita dari sumber-sumber yang terpercaya. Dengan media offline yaitu melalui sosialisasi atau bertemu langsung dengan masyarakat setempat juga dengan membuat selebaran atau leflet, buletin atau pin yang dibagikan ke masyarakat. Cara ini ditempuh oleh KIM Mojo dikarenakan sebagian masyarakat yang berada di wilayah Mojo berada di bawah rata-rata. Selain itu, KIM Mojo juga mengupayakan program literasi untuk anak-anak melalui program mendongeng di setiap minggu.

3. Hambatan Implementasi KIM di Wilayah Urban (KIM Mojo dan KIM Swaraguna)

Ketersediaan infrastruktur dan jaringan internet belum menjamin kemampuan masyarakat untuk mengakses informasi melalui internet. Karena di wilayah kelurahan Mojo dan juga Kecamatan Gunung Anyar, masih memiliki penduduk yang tidak memiliki kemampuan menggunakan teknologi yang mendukung pencarian informasi melalui internet, sehingga masih terdapat kesenjangan di antara masyarakat mengenai penggunaan atau akses informasi melalui internet. Selain masih banyaknya masyarakat yang belum menguasai teknologi, hambatan lainnya ialah kurangnya kesadaran akan pentingnya 
informasi di masyarakat. Obyek permasalahannya yakni masyarakat golongan tua dan juga sebagian kecil masyarakat yang berada dalam golongan ekonomi rendah.

4. Capaian KIM di Wilayah Urban (KIM Mojo dan KIM Swaraguna)

KIM Swaraguna saat ini sedang mengupayakan pencapaian fungsi KIM sebagai wahana penyebar informasi. Hingga saat ini KIM Mojo melakukan konsistensi untuk menyebarkan informasi melalui media online dan juga media offline kepada masyarakat di wilayah Mojo.

\section{Pembahasan}

a. Proses Pembentukan KIM

Proses pembentukan KIM idealnya dibentuk secara mandiri. Proses pembentukan secara mandiri akan mempengaruhi bagaimana KIM tersebut dijalankan dan mencapai tujuan dari dibentuknya KIM. Pada kasus KIM Mojo, diawali dengan proses pembentukan secara mandiri atas kesadaran kebutuhan KIM, KIM dapat berjalan lebih baik dibandingkan dengan kelompok KIM lain yang dibentuk melalui proses penunjukkan. Sebagai pembanding ialah KIM Warurejo dan KIM Nglanduk. Kedua KIM tersebut adalah kelompok informasi yang dari pembentukkan hingga saat ini bersifat pasif atau tidak memiliki aktivitas. Sedangkan KIM Swaraguna, meskipun melalui proses pembentukan yang sama dengan KIM Warurejo dan juga KIM Nglanduk namun para anggota KIM Swaraguna memiliki kesadaran kebutuhan KIM untuk masyarakat Gunung Anyar. Dari proses pembentukan empat KIM tersebut, peneliti melihat bahwa proses pembentukan KIM merupakan awal yang penting untuk keberhasilan program KIM. Perbedaan proses pembentukan KIM, akan mempengaruhi bagaimana sebuah kelompok dijalankan.

\section{b. Aktivitas KIM di Wilayah Rural dan Urban}

KIM yang berada di wilayah rural, KIM Warurejo dan KIM Nglanduk merupakan KIM yang pasif. Kedua kelompok ini, memiliki kasus yang sama. Semenjak pembentukannya, KIM Warurejo dan juga KIM Nglanduk tidak mampu menjalankan aktivitas sesuai dengan visi dan misi kelompok masing-masing. Kondisi ini merupakan sebuah kegagalan karena KIM tidak mampu menjalankan fungsi dan tugas. Ketika sebuah kelompok KIM tidak mampu menjalankan tugas dan fungsinya, maka tujuan program KIM untuk memberdayakan masyarakat hingga tercapai masyarakat informasi tidak akan tercapai.

KIM Swaraguna memiliki proses pembentukan yang sama dengan KIM Warurejo dan KIM Nglanduk. Namun pada tahap selanjutnya setelah pembentukan, dengan adanya dukungan dan keikutsertaan beberapa anggota masyarakat Kecamatan Gunung Anyar, KIM Swaraguna mampu menjalankan aktivitasnya dalam menyebarkan informasi kepada masayarakat secara online. Hal ini dipengaruhi oleh adanya kesadaran dari anggota KIM bahwa KIM harus mampu menyebarkan informasi yang merupakan sebuah kebutuhan untuk masyarakat di Kecamatan Gunung Anyar. Namun, aktivitas-aktivitas yang dijalankan oleh KIM Swaraguna belum mampu mencakup aktivitas pokok KIM yang ideal. KIM Mojo di Kelurahan Mojo Kota Surabaya, memiliki aktivitas-aktivitas berkaitan dengan akses informasi, diskusi informasi, dan diseminasi informasi. Aktivitas penyebaran informasi melalui media online dan offline oleh KIM Mojo merupakan cara penyebaran informasi yang mampu mencakup secara luas masyarakat. Dari media yang digunakan oleh KIM Mojo menyebarkan informasi, memperlihatkan bahwa KIM Mojo memiliki komitmen lebih baik dibandiingkan kelompok lainnya.

\section{c. Hambatan Implementasi Program KIM}

Implementasi program KIM baik di wilayah rural maupun urban masih banyak mengalami hambatan. Hambatan bukan hanya pada pelaksanaan aktivitas, namun hambatan juga terdapat pada awal implementasi program KIM yaitu proses pembentukan KIM. Hambatan yang paling mempengaruhi implementasi program KIM ialah ketersediaan infrastruktur, komitmen dan kecakapan anggota KIM, dan kesadaran dan kepedulian masyarakat terhadap program KIM.

Ketersediaan infrastruktur teknologi informasi dan juga komunikasi ikut berpengaruh terhadap bagaimana KIM dijalankan. Permasalahan ini dialami oleh KIM Warurejo dan juga KIM Nglanduk. Mereka mengalami kesulitan untuk mendapatkan akses 
internet yang memadai. Hal tersebut berpengaruh pada program KIM masingmasing.

Komitmen anggota KIM dalam menjalankan tugas akan terlihat ketika KIM mampu menjalankan tugasnya dengan baik. Dari keempat kelompok yang menjadi obyek penelitian, komitmen anggota KIM akan dapat dilihat dari aktivitas-aktivitas yang dijalankan. Aktivitas-aktivitas yang mengarah pada tujuan dibentuknya KIM akan semakin menunjukkan bahwa para anggota KIM yang tergabung dalam kelompok tersebut memiliki komitmen yang cukup baik dalam menjalankan KIM yang terlihat pada kelompok KIM di wilayah urban yakni KIM Mojo dan KIM Swaraguna. Sebaliknya komitmen anggota KIM cenderung rendah akan terlihat pada bagaimana aktivitasaktivitas KIM tidak mampu berjalan dengan optimal yang terlihat pada KIM di wilayah rural yakni KIM Warurejo dan KIM Nglanduk.

Masuknya KIM di wilayah rural tersebut mengalami banyak kendala. Salah satunya ialah kurangnya rasa kepedulian dan kesadaran masyarakat terhadap KIM. Masyarakat di Desa Nglanduk dan juga di Desa Warurejo cenderung bersikap acuh terhadap keberadaan KIM di desa mereka masing-masing. Bukti nyata dari kurangnya kesadaran dan kepedulian masyarakat terhadap KIM Warurejo dan juga KIM Nglanduk ialah tidak adanya masyarakat yang ikut serta bergabung dalam kepengurusan KIM baik menjadi anggota KIM maupun pengurus lainnya. Berbeda dengan kondisi masyarakat di wilayah urban, masyarakat di wilayah tersebut cenderung lebih peduli. Meskipun kepedulian masyarakat tidak sepenuhnya besar terhadap keberadaan KIM di lingkungan tempat tinggal mereka. Buktinya masih adanya beberapa anggota masyarakat yang bergabung dalam keanggotaan KIM baik di KIM Swaraguna maupun di KIM Mojo Kota Surabaya.

\section{d. Capaian Implementasi Program KIM}

Indikator yang menjadi ukuran keberhasilah diraihnya capaian implementasi program KIM ialah tercapainya fungsi KIM oleh masing-masing kelompok KIM. Indikator tersebut yakni telah terwujudnya KIM sebagai wahana informasi, mitra dialog pemerintah, lembaga yang memiliki nilai ekonomi, sarana peningkatan literasi informasi, media massa dan teknologi komunikasi.
Dari empat kelompok KIM yang menjadi obyek penelitian, hanya dua kelompok KIM yang berada di wilayah urban yakni KIM Mojo dan juga KIM Swaraguna yang masih berupaya mewujudkannya. Sementara harapan tercapainya masyarakat informasi di Desa Warurejo dan juga Desa Nglanduk Kabupaten Madiun untuk saat ini harus ditunda. Hal ini karena KIM Warurejo dan KIM Nglanduk merupakan kelompok yang pasif, tidak ada kegiatan yang dilakukan oleh KIM dalam upaya memberdayakan masyarakat. Sementara di wilayah urban, KIM telah mengupayakan untuk mewujudkan semua fungsi KIM meskipun saat ini masih banyak yang harus diperbaiki agar semua fungsi dapat tercapai.

\section{Pencapaian Masyarakat Informasi}

Berdasarkan hasil dari penelitian yang menggunakan empat kelompok KIM di wilayah rural dan di wilayah urban, peneliti menyimpulkan bahwa sebenarnya Indonesia masih belum siap untuk menyongsong masyarakat informasi. Hal ini dapat dilihat dari bagaiamana capaian KIM sampai saat ini. Terutama bila dilihat dari bagaiamana kondisi KIM di wilayah rural yang belum mampu menjalankan program tersebut.

Masyarakat di wilayah urban memiliki tingkatan yang lebih baik dibandingkan dengan masyarakat di wilayah rural. Hal ini terlihat dari bagaimana masyarakat memaknai informasi dan memanfaatkan untuk kehidupan mereka. Meskipun-, belum keseluruhan masyarakat di wilayah urban telah mampu mengoptimalkan pemanfaatan informasi. Misalkan saja hanya terdapat beberapa anggota masyarakat saja yang mampu memanfaatkan teknologi informasi dan komunikasi serta informasi terkait pasar untuk menjalankan sebuah bisnis online. Anggota masyarakat tersebut telah masuk pada tingkatan kedua yakni masyarakat kaya informasi

\section{E. KESIMPULAN}

Kesimpulan yang dapat ditarik dari penelitian ini ialah terwujudnya masyarakat informasi masih menjadi keinginan yang harus terus diupayakan oleh Pemerintah Indonesia. Hal ini karena berdasarkan dari penelitian terlihat bahwa masyarakat masih belum berada pada tingkatan ketiga dalam sebuah tingkatan masyarakat informasi yakni masyarakat yang berbasis pengetahuan. Kondisinya, masyarakat Indonesia mayoritas masih berada pada tingkatan 
pertama yakni masyarakat sadar informasi. Bahkan beberapa wilayah rural masih pula ada masyarakat yang belum sadar akan informasi seperti masyarakat di wilayah rural yang cenderung acuh terhadap informasi yang tidak memiliki keterkaitan langsung pada kehidupan mereka.

Saran untuk penelitian-penelitian selanjutnya ialah perlunya penelitian yang lebih mendalam mengenai implementasi KIM bukan hanya dari perspektif pelaksana program namun juga perspektif pemangku kebijakan dan juga masyarakat. Hal ini agar mampu memberikan gambaran yang lebih jelas dan rinci mengenai program KIM. Saran untuk program KIM ialah, perlunya evaluasi program. Evaluasi tersebut perlu dilakukan pada aspek ketersediaan infrastruktur, kecakapan sumber daya masyarakat untuk menjadi anggota KIM, kesiapan masyarakat untuk menerima program KIM.

\section{DAFTAR PUSTAKA}

Dahlman, Carl. 2015. Technology, globalization, and international competitiveness: Challenges for developing countries. Georgetown University, Edmund A. Walsh School of Foreign Service, pp:29.

Djunaedi, Akhmad. 2015. Teknologi Informasi Peran dan Fungsinya dalam. Dunia Perpustakaan. Pustaka. LP3ES Indonesia, pp:20.

Miles, Matthew dan Huberman, A.Michael. 1992. Analisis Data Kualitatif: Buku Sumber Tantang Metode-Metode Baru. Jakarta:UI Press, pp:20.
Palyviou, Zachos A. 2007. The Information Society:Advantages and Disadvantages. Cyprus: University of Wales, pp:3.

Verzosa, Fe Angela. 2009. User Education and Information Literacy: Current Practices and Innovative Strategies. diakses melalui http://www.slideshare.net/verzosaf/usereducation-andinformationLiteracyinnovative-strategies-and-practices pada 12 November 2016

Global Competitiveness 2016-2017 diakses melalui http://www3.weforum.org/docs/GCR20162017/05FullReport/TheGlobalCompetitivene ssReport2016-2017_FINAL.pdf pada 20 Desember 2016

Global Information Technology Report (GTIR) 2016 melalui https://www.mckinsey.de/files/ mgi_digital_globalization.pdf diakses pada 22 desember 2016

Peraturan Menteri Komunikasi dan Informatika $\mathrm{R}$ e p u b 1 i k I n d o n e s i a No.08/PER/M.KOMINFO/6/2010 tentang Pedoman Pengembangan dan Pemberdayaan Lembaga Komunikasi Sosial melalui https://jdih.kominfo.go.id/produk_hukum/vie $\mathrm{w} / \mathrm{id} / 254 / \mathrm{t} /$ peraturan + menteri + komunikasi $+\mathrm{d}$ an+informatika+nomor+08permkominfo 062 $010+$ tanggal $+01+$ juni +2010 diakses pada 1 Januari 2017 